\title{
Effects of the Prenatal Administration of Tetanus Toxoid on the Sociability and Explorative Behaviors of Rat Offspring: A Preliminary Study
}

\author{
Eda Sünnetçi', Ferit Durankuş ${ }^{2}$, Yakup Albayrak ${ }^{3}$, Mümin Alper Erdoğan ${ }^{4}$, Özüm Atasoy ${ }^{5}$, Oytun Erbaş ${ }^{6}$ \\ ${ }^{1}$ Department of Pediatrics, Istanbul Training and Education Hospital, ${ }^{2}$ Department of Pediatrics, Istanbul Medeniyet University, Istanbul, \\ ${ }^{3}$ Department of Psychiatry, Faculty of Medicine, Tekirdağ Namık Kemal University, Tekirdağ, ${ }^{4}$ Department of Physiology, Katip Çelebi University \\ Medical School, Izmir, ${ }^{5}$ Department of Radiation Oncolgy, Kartal Education and Research Hospital, ${ }^{6}$ Department of Physiology, Demiroğlu Bilim \\ University Medical School, Istanbul, Turkey
}

Objective: Autism spectrum disorder (ASD) is a severely disabling psychiatric disease characterized by impairments in communication and social skills. Although efforts have been made to explore the etiology of ASD, its pathophysiology remains unclear. This issue is rendered more challenging by confounding data about the effects of vaccination on disease etiology. In this study, therefore, we investigated the neurodevelopmental effects of maternal tetanus toxoid administration on rat offspring. We hypothesized that the vaccine affects the sociability and preference for social novelty of rat offspring as well as the production of immunological and neurotrophic factors, including tumor necrosis factor-alfa (TNF- $\alpha$ ), neuregulin-1 (NRG-1), neuron growth factor (NGF), and oxytocin.

Methods: The study involved 12 female and 4 male adult Sprague-Dawley rats $(238 \pm 10 \mathrm{~g})$, which were assigned to two groups. Group 1 (control group) was given $0.5 \mathrm{ml}$ of normal saline $(0.9 \% \mathrm{NaCl})$ on the 10 th day of pregnancy, whereas Group 2 (experimental group) was administered $0.5 \mathrm{ml}$ of tetanus vaccine (tetanus toxoid, $40 \mathrm{IU}$ ).

Results: Maternal tetanus toxoid administration exerted beneficial effects on the sociability and explorative behaviors of the rats. The brain tissue levels of TNF- $\alpha, N G F, N R G-1$, and oxytocin were higher in the experimental group than those among the controls. All these significant differences were found in both the male and female rats.

Conclusion: This study is the first to demonstrate the advantages of tetanus toxoid administration in relation to the sociability and explorative behaviors of rat offspring. The results showed that the vaccine also influences NRG-1, neuregulin, and oxytocin production.

KEY WORDS: Autism; Vaccination; Tetanus; Inflammation; Neurogenesis.

\section{INTRODUCTION}

Autism spectrum disorder (ASD) is an extremely incapacitating psychiatric illness that is characterized by impairments in the communication, social, and psychomotor domains [1-3] ASD and related issues have been increasingly illuminated, but the exact etiology of the disease remains unclear. Some factors that are suspected to

Received: March 10, 2020 / Revised: June 21, 2020

Accepted: June 24, 2020

Address for correspondence: Yakup Albayrak

Department of Psychiatry, Faculty of Medicine, Tekirdağ Namık

Kemal Üniversitesi, Tıp Fakültesi 59100, Süleymanpaşa,

Tekirdağ, Turkey

E-mail: dr.fuge@hotmail.com

ORCID: https://orcid.org/0000-0002-1926-1695 be contributory to ASD etiology are environmental, genetic, infection-related, metabolic, and immunological attributes. Nevertheless, the symptoms and signs of ASD cannot be attributed to a single mechanism [4-7].

With regard to environmental factors, several viral infections and some kinds of drugs have been associated with the development of ASD. In particular, the stimulation of maternal immunological pathways by bacteria and viruses have been viewed as causing significant neurochemical alterations in offspring [8]. This orientation directed attention to maternal vaccination during pregnancy as a possible route to ASD development in children. Some studies revealed that maternal immune activation increases the risk of ASD [1,8], while animal ASD models based on such activation indicated that disease develop-

@) This is an Open-Access article distributed under the terms of the Creative Commons Attribution Non-Commercial License (http://creativecommons.org/licenses/by-nc/4.0) which permits unrestricted non-commercial use, distribution, and reproduction in any medium, provided the original work is properly cited. 
ment is induced by bacterial or viral infections [9-11]. However, epidemiological and experimental studies reported contrasting findings [12-18], thereby precluding a definitive conclusion regarding the involvement of maternal vaccination in the development of ASD.

Experimental studies showed that prenatal influenza vaccination is associated with neurogenesis both in pregnant mice and their offspring [12,13]. Xia et al. [12], for example, reported that maternal influenza vaccination enhances exploratory behaviors and improves the spatial cognitive performance of offspring in Morris water maze tests. Other researchers discovered that influenza vaccination promotes $\mathrm{M} 2 \mathrm{microg}$ lial/macrophage polarization via the neuronal secretion of brain-derived neurotrophic factor (BDNF) [15]. Explorations into associations between vaccination during pregnancy and ASD development likewise extend to epidemiological studies. A case in point is the work of Zerbo et al. [18], who uncovered that influenza vaccination does not increase ASD risk among children whose mothers received the vaccine. Similar results were derived in a study grounded in data from seven vaccine safety data link sites [19]. More recent work by Becerra-Culqui et al. [20] negated the connection of elevated ASD risk to prenatal tetanus, diphtheria, and acellular pertussis vaccinations.

As can be seen, the present-day scholarship on the etiology and pathophysiology of ASD has thus far generated mixed results. For more conclusive insights into these issues, the present study was conducted to determine the neurodevelopmental effects of maternal tetanus toxoid administration on rat offspring. We hypothesized that tetanus toxoid affects the sociability and preference for social novelty of rat offspring as well as the production of immunological and neurotrophic factors, such as tumor necrosis factor-alfa (TNF- $\alpha$ ), neuregulin-1 (NGF-1), neuron growth factor (NGF), and oxytocin.

\section{METHODS}

\section{Animals}

The study involved 12 female and 4 male adult SpragueDawley rats (238 $\pm 10 \mathrm{~g}$ ), which were housed in plastic cages under standard conditions, with 12 hours light/dark cycles implemented at room temperature $\left(22 \pm 2^{\circ} \mathrm{C}\right)$. All animal studies strictly adhered to the animal experiment guidelines issued by the Institutional Animal Care and
Ethics Committee (approval number: 199545701/3A).

\section{Study Design}

The female rats were randomly distributed into two groups: Group 1, which served as the controls $(n=6)$, and Group 2, to which tetanus toxoid was administered ( $\mathrm{n}=$ 6). All the animals were monitored daily for behavioral and health changes throughout the study. The female rats were caged with a fertile male (three females/one male) for two to three days, and mating was confirmed via an examination of white vaginal plaque in the females. After this, the male rats were removed from the cages.

The Group 1 rats were given $0.5 \mathrm{ml}$ of normal saline $(0.9 \% \mathrm{NaCl})$ on day 10 of pregnancy, whereas the Group 2 rats were administered $0.5 \mathrm{ml}$ of tetanus vaccine (tetanus toxoid, 40 IU) (Tetavax; Sanofi Pasteur, Lyon, France) also on day 10 of pregnancy. On the day of birth, litter size was reduced to nine pups per dam to ensure standardized maternal care. The dams were allowed to raise their own litters until weaning on postnatal day 21 (P21). On P21, 40 littermates (10 male controls, 10 female controls, 10 male tetanus toxoid-exposed rats, and $10 \mathrm{fe}-$ male tetanus toxoid-exposed rats) were randomly separated and housed in same-sex and same-study group cages with ad libitum access to standard food and tap water. All analyses were performed using a sex-specific evaluation. Considering that the male to female sex ratio is $2-3: 1$ for autism in humans [21], we made all analysis according to sex. These animals were then subjected to behavioral testing upon reaching adulthood on P50. All behavioral experiments were conducted between 10:00 AM and 3:00 PM.

\section{Behavioral Tests}

\section{Three-chamber sociability and social novelty test}

Sociability test was performed as previously described with minor modifications $[22,23]$. Briefly, a Plexiglas cage $(40 \mathrm{~cm} \times 90 \mathrm{~cm} \times 40 \mathrm{~cm})$ was divided into three equal regions $(40 \mathrm{~cm} \times 30 \mathrm{~cm} \times 40 \mathrm{~cm})$. On the first day, the rats were allowed to habituate in the test cage for $5 \mathrm{mi}$ nutes (pre-test session). Twenty-four hours later, to test sociability, a stranger rat (Stranger 1) was placed inside a small plastic cage with mesh-like holes in one side chamber and an empty cage in the third chamber. Then, the test rat was placed in the center chamber and the time spent in 
each region by the test rat was recorded for 10 minutes (Session I). For the social novelty and motivation test, an unfamiliar rat (Stranger 2) was then placed in the opposite side chamber, and the time spent in each region by the test rat was recorded for a further 10 minutes (Session II). The test rat was considered to be in the chamber when its head and two front paws entered the chamber. The floor of the field was then cleaned between each test with a $70 \%$ alcohol and dried with paper towel to remove any traces of olfactory stimuli from the previous rat (Fig. 1).

\section{Open-field test}

The open-field (OF) paradigm is one of the popular behavioral tests to assess locomotion and exploration. Altered OF behavior is relatively simple to observe; however, concluding the reasons for the observed changes is a complex task. Generally, there are two factors that determine the behavior in this paradigm: The first is a positive exploratory drive originating from the nature of rodents to explore new environments (for food and shelter), and the second is the animal nature of avoiding open and brightly lit spaces (exposure to predators). The open-field test is considered useful in determining motor stereotyped

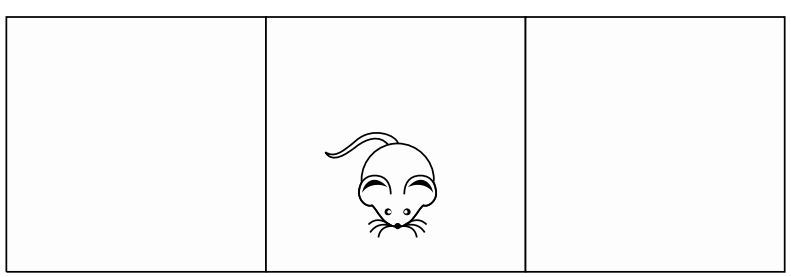

Pre-test session

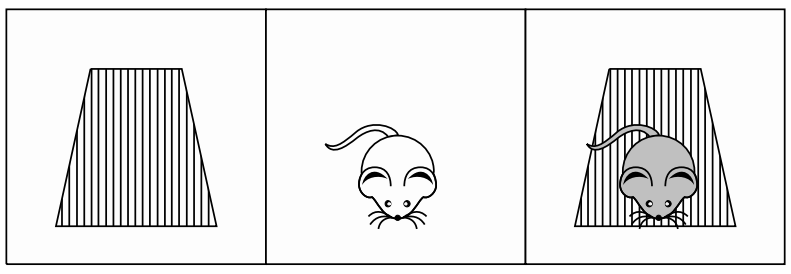

Sociability test (session I)

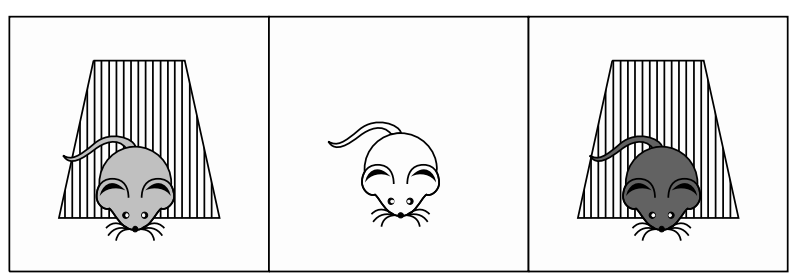

Social novelty and motivation test (session II)

Fig. 1. Three-chamber sociability and social novelty test. behavior, repeated autogrooming, and restriction of research activity in autism model [24]. The open-field test was conducted in an open-aired box with dimensions of $50 \mathrm{~cm} \times 50 \mathrm{~cm} \times 40 \mathrm{~cm}$. At the beginning of the test, rats were gently placed in the center of the box and allowed to explore the arena freely for 5 minutes. Then, each rat was observed for 5 minutes to evaluate its spontaneous activity level. The total number of ambulation (i.e., the number of floor divisions crossed with four paws) was recorded. The floor of the field was then cleaned between each animal with a $70 \%$ alcohol-water solution and dried with paper towel to avoid olfactory cues [25].

\section{Tissue Biochemical Analysis}

After decapitation, brains were rapidly removed and stored at $-20^{\circ} \mathrm{C}$ until the time of biochemical analysis. For tissue analysis, whole cerebral tissues were homogenized with a glass homogenizer in $5 \%$ of phosphate-buffered saline $(\mathrm{pH}, 7.4)$ and centrifuged at 5,000 $g$ for 15 minutes. The supernatant was then collected and total protein concentration in the brain homogenates was determined according to Bradford's method using bovine serum albumin as standard [26].

The brain levels of TNF- $\alpha$ (Shanghai LZ Biotech Co., Ltd., Shanghai, China), NGF (MyBioSource, Inc., San Diego, CA, USA), oxytocin (MyBioSource, Inc.), NRG1 (Shanghai LZ Biotech Co., Ltd.) in the tissue supernatants were measured using commercially available rat enzyme-linked immunosorbent assay (ELISA) kits. All samples from each animal were measured in duplicate according to the manufacturer's guidelines.

\section{Statistical Analysis}

Statistical evaluation was performed using the Statistical Package for the Social Sciences (version 15.0 for Windows, SPSS Inc., Chicago, IL, USA). The Shapiro-Wilk and Levene's tests were conducted to verify the normality of the data and the homogeneity of variance, respectively. The groups were compared with ANOVA test. Post-hoc analysis was performed with Tukey test. The results are presented as mean \pm standard error of the mean. A value of $p<0.05$ was considered reflective of statistical significance. 


\section{RESULTS}

\section{Effects of Prenatal Tetanus Toxoid on Sociability and Preference for Social Novelty}

Prenatal tetanus toxoid enhanced the sociability and preference for social novelty of the examined offspring. To detect the effects of maternal tetanus toxoid administration on the social behaviors of the rats, we carried out a three-chamber social test, during which rats normally choose to spend a considerable amount of time in a compartment containing another rat. Both the male and female rats in study group spent significantly more time in the compartment compared with their counterparts (Session I [sociability test]) $(p<0.005$ and $p<0.001$, respectively). Both the male and female rats exhibited better preference for social novelty compared with their counterparts (Session II [social novelty]) $(p<0.05$ and $p<$ 0.001 , respectively) (Table 1 ).

\section{Effects of Prenatal Tetanus Toxoid on Open-field Test}

The male and female rats in the control group had significantly higher scores than their counterparts in the experimental/vaccinated group on open field test $(p<0.05$ and $p<0.001$, respectively) (Table 1 ).

\section{Effects of Prenatal Tetanus Toxoid on Biochemical Alterations in the Brain}

Table 2 presents the results on biochemical markers (TNF- $\alpha$, NGF, NRG-1, and oxytocin) in the brain samples obtained from the control and tetanus toxoid-exposed rats. The TNF- $\alpha$ levels in the male and female control rats were $21.4 \pm 2.5 \mathrm{ng} / \mathrm{mg}$ and $22.8 \pm 3.3 \mathrm{ng} / \mathrm{mg}$, respec-

Table 1. Comparison of scores of three chamber tests and open field test between groups

\begin{tabular}{cccc}
\hline Parameters & Control group & Study group & $p$ value \\
\hline Three-chamber sociability and social novelty test & \\
\multicolumn{4}{c}{ Session-I (Stranger 1. compartment duration) } \\
Male & $415.6 \pm 33.8$ & $572.3 \pm 13.4$ & $<0.05$ \\
Female & $324.7 \pm 24.9$ & $554.7 \pm 16.9$ & $<0.001$ \\
Session-II (Stranger 2. compartment duration) & \\
Male & $411.6 \pm 53.2$ & $596.1 \pm 21.8$ & $<0.05$ \\
Female & $385.3 \pm 38.7$ & $583.5 \pm 26.3$ & $<0.05$ \\
Open field test (number of ambulation) & \\
Male & $14.8 \pm 2.3$ & $24.5 \pm 4.6$ & $<0.001$ \\
Female & $18.6 \pm 3.1$ & $48.2 \pm 7.8$ & $<0.001$ \\
\hline
\end{tabular}

Values are presented as mean \pm standard deviation of the mean. tively, whereas TNF- $\alpha$ concentrations in the male and female experimental rats were $36.7 \pm 4.8 \mathrm{ng} / \mathrm{mg}$ and $33.6 \pm$ $5.3 \mathrm{ng} / \mathrm{mg}$, respectively. The brain tissue levels of TNF- $\alpha$ in the male and female experimental rats were significantly higher compared to those in the controls ( $p<$ 0.05 and $p<0.005$, respectively). The male and female rats in the control group had NRG-1 concentrations of $4.1 \pm$ $0.3 \mathrm{pg} / \mathrm{mg}$ and $2.9 \pm 0.8 \mathrm{pg} / \mathrm{mg}$, respectively. By contrast, concentrations in the experimental group amounted to $6.8 \pm 1.1 \mathrm{pg} / \mathrm{mg}$ and $5.6 \pm 0.7 \mathrm{pg} / \mathrm{mg}$, respectively. The experimental group had significantly higher levels of NRG-1 than the control group ( $p<0.05$ and $p<0.005$, respectively). As for the NGF levels, the male and female controls and the male and female vaccinated rates registered concentrations of $65.7 \pm 5.8 \mathrm{pg} / \mathrm{mg}$ and $56.9 \pm 14.3$ $\mathrm{pg} / \mathrm{mg}$ and $89.3 \pm 9.4 \mathrm{pg} / \mathrm{mg}$ and $91.5 \pm 10.2 \mathrm{ng} / \mathrm{mg}$, respectively. The brain tissue levels of NGF in the male and female rats in the vaccination group were significantly higher compared to those of the control group ( $p<$ 0.05 and $p<0.005$, respectively). The oxytocin levels were $78.5 \pm 11.4 \mathrm{pg} / \mathrm{mg}$ and $85.6 \pm 9.5 \mathrm{pg} / \mathrm{mg}$ in the male and female control rats, respectively. These levels amounted to $135.2 \pm 12.6 \mathrm{pg} / \mathrm{mg}$ and $128.8 \pm 17.1 \mathrm{pg} / \mathrm{mg}$ in the male and female vaccine-administered rats, respectively. The experimental group exhibited significantly higher brain tissue levels of oxytocin than the control group ( $p<$ 0.05 and $p<0.005$, respectively).

Table 2. Comparison of brain levels of TNF- $\alpha$, NRG-1, NGF, and oxytocin between groups

\begin{tabular}{|c|c|c|c|}
\hline Parameters & Control group & Study group & $p$ value \\
\hline \multicolumn{4}{|l|}{ TNF- $\alpha$ (ng/mg) } \\
\hline Male & $21.4 \pm 2.5$ & $36.7 \pm 4.8$ & $<0.05$ \\
\hline Female & $22.8 \pm 3.3$ & $33.6 \pm 5.3$ & $<0.05$ \\
\hline \multicolumn{4}{|c|}{ NRG-1 (pg/mg) } \\
\hline Male & $4.1 \pm 0.3$ & $6.8 \pm 1.1$ & $<0.05$ \\
\hline Female & $2.9 \pm 0.8$ & $5.6 \pm 0.7$ & $<0.05$ \\
\hline \multicolumn{4}{|l|}{ NGF (pg/mg) } \\
\hline Male & $65.7 \pm 5.8$ & $89.3 \pm 9.4$ & $<0.05$ \\
\hline Female & $56.9 \pm 14.3$ & $91.5 \pm 10.2$ & $<0.05$ \\
\hline \multicolumn{4}{|c|}{ Oxytocin (pg/mg) } \\
\hline Male & $78.5 \pm 11.4$ & $135.2 \pm 12.6$ & $<0.001$ \\
\hline Female & $85.6 \pm 9.5$ & $128.8 \pm 17.1$ & $<0.001$ \\
\hline
\end{tabular}




\section{Correlation between Sociability, Social Novelty, and Biochemical Parameters}

We conducted Pearson correlation test between values of sociability and social novelty between brain levels of TNF- $\alpha$, NGF, NRG-1, and oxytocin in the study group. There was significant positive correlation between sociability and NGF, NRG-1, and oxytocin $(r=0.65, p<$ $0.01 ; r=0.72, p<0.001$; and $r=0.77, p<0.001$; respectively). Similarly, there was significant positive correlation between social novelty and NGF, NRG-1, and oxytocin $(r=0.56, p=0.02 ; r=0.69, p<0.001$; and $r=$ $0.73, p<0.001$; respectively).

\section{DISCUSSION}

This study demonstrated that maternal tetanus toxoid administration was beneficial to sociability and explorative behaviors. The brain tissue levels of TNF- $\alpha$, NGF, NRG-1, and oxytocin were higher in the experimental rats compared to those in the control animals. All these significant differences were found in both the male and female rats.

Accumulating evidence has been derived regarding the strong association of genetic vulnerabilities and environmental factors with ASD. Particularly harmful environmental factors during pregnancy can affect offspring behaviors, and they can be implicated in neurodevelopmental disorders. Although human studies have identified no link between tetanus toxoid administration and an increased risk of ASD development [20], the exact mechanism underlying the pathogenesis in this respect has not been thoroughly explained.

Impairments in social interaction, communication, and explorative behaviors are the core features of ASD $[27,28]$, but several other symptoms and psychiatric diagnosis are commonly seen in clinical settings [29]. In this research, we used structured protocols to evaluate behavioral alterations that are related to the neurodevelopmental aspects of autism. We performed a three-chamber sociability procedure to evaluate the rats for signs of reduced social functioning observed in autism. We found that the male and female rats in the experimental group had significantly higher scores than those obtained by their counterparts in the control group. On this basis, we argue that the administration of tetanus toxoid during pregnancy can be considered safe and possibly beneficial to the prevention of autism development in offspring.

NRG-1 is a growth factor that regulates several processes involved in the maintenance of neuronal networks and neuroplasticity. It works with the ErbB receptor tyrosine kinase, which is a member of the epidermal growth factor receptor family. It mainly affects GABAergic transmission and regulates synchronized network activity [30]. Dysregulation in an NRG-1 system was reported as an etiological factor in a number of psychiatric diseases, such as schizophrenia, bipolar disorder, and Alzheimer's disease [31,32]. Additionally, neurotrophic factors such as NGF and BDNF play important roles in neuronal growth, survival, and synapse formation [33]. Nevertheless, conflicting results have been obtained about the levels of neurotrophic factors and NRG-1 in individuals with ASD (e.g., increased or unchanged levels), but these findings were based on detection in circulating peripheral blood samples $[31,34,35]$. In our study, we used brain tissue samples, so the levels found can be considered more representative of concentrations in a living brain.

Available data suggested that the dysregulation of the cytokine system is instrumental in the immunopathogenesis of ASD. An assessment of brain tissues indicated that patients with ASD showed increased proinflammatory chemokines [36]. Similarly, in vitro studies found evidence of the elevated production of proinflammatory and regulatory cytokines by peripheral blood mononuclear cells in patients with ASD [37]. Furthermore, inflammatory responses were identified as correlated with the severity of ASD's behavioral symptoms [8]. In a recent metaanalysis, however, no significant differences were found between patients with ASD and healthy controls in terms of serum TNF- $\alpha$ concentrations [38]. Meta-regression analyses also pinpointed a significant effect of differences in the percentage of males between patients and controls. These results implied that the role of TNF- $\alpha$ in the etiopathogenesis of ASD is unclear. The current research found that TNF- $\alpha$ concentrations were significantly higher in the brain tissues of the experimental group compared to those in the brain tissues of the control group. This finding is attributed to the inflammatory response of brain tissue to tetanus toxoid and thus explains the successful administration of tetanus toxoid administration in the experimental group. Another explanation for the higher TNF- $\alpha$ levels in the experimental group is mild stress activity. Stress is typically regarded as a beneficial experience that 
motivates organisms to act and overcome a stressful challenge. In certain conditions, however, stress can be chronic and exert harmful and devastating effects. Some kinds of stress that are experienced prenatally can influence neuronal plasticity and survival $[39,40]$. Researchers also asserted that premature infants exposed to stress-related conditions might express increased levels of proinflammatory cytokines, such as TNF- $\alpha$, interleukin-1 (IL-1), and IL-6 [41]. Ashwood et al. [8] reported increased cytokine and chemokine concentration, along with activated microglia, in the postmortem brains of ASD patients, leading to the conclusion that the dysregulation of the cytokine system in the central nervous system (CNS) adversely affects behavior through alterations in neuronal growth and activity $[42,43]$. However, increased TNF- $\alpha$ levels were also found to be associated with elevated BDNF in an activity-dependent manner [44].

The relationship between TNF- $\alpha$ and oxytocin is complicated. Studies indicated that oxytocin can also act as an antioxidant during oxidative stress and that its concentrations can rise as a reaction to the production of inflammatory chemokines or cytokines, such as TNF- $\alpha$ [45]. We posit that the administration of tetanus toxoid would act as a mild form of stress on the CNS of offspring, and TNF- $\alpha$ might trigger increased neuregulin, NRG-1, and oxytocin. Nonetheless, further clinical and experimental investigations are needed to shed light on how TNF- $\alpha$ factors in the etiopathogenesis of ASD.

Oxytocin is a peptide hormone strongly associated with the social behaviors of mammals. An increasing number of reports have illustrated oxytocin's principal role in the social functioning of animals and humans, particularly children and adults with ASD [46-48]. Moreover, intranasal oxytocin administration was demonstrated to improve social functioning and empathy in healthy individuals $[47,49]$. Currently, the treatment approach involving oxytocin is considered suitable for children with ASD. Genetic variations in alleles of oxytocin receptor genes (OXTR), promoter methylation, and/or expression levels in some areas of the brain responsible for social function may be related to the variable responses to intranasal oxytocin administration during clinical trials on ASD [50,51]. Several experimental studies showed differences in OXTR expression levels in the amygdala, the nucleus accumbens, and the prefrontal cortex [52]. Clinical and experimental research also satisfactorily established the strong association of oxytocin concentrations and associated genetic variations with social behaviors [53]. In the present work, both the male and female rats in the experimental group had significantly higher oxytocin levels than those observed in the control group. This result aligns with studies presenting a significant association between oxytocin and improved social behaviors. This also means our research is the first to demonstrate the effects of tetanus toxoid on oxytocin levels in brain tissue.

Present study may provide that tetanus toxoid will enhance several mechanism such as increasing levels of oxytocin, neuroglin and NRG-1 in the brain tissue of rats. Considering the higher level of TNF- $\alpha$, the most reasonable mechanism seems to be reaction of CNS to mild stress. However, the interactions of neurotransmitters are quite complex and there might be further mechanisms which should be explained with future studies. As a result, we can say that tetanus toxoid is not only safe; it might be also protective in terms of development of autism spectrum disorder.

The limitations of the study are worth noting. Although we administrated the three- chamber sociability and social novelty test and the open field test for the assessment of sociability and explorative behaviors, the model employed in this work might be considered insufficient for evaluating all the symptoms of ASD. We also disregarded the assessment of brain tissue as a specific bodily component.

In conclusion, this study is the first to demonstrate the beneficial effects of tetanus toxoid on sociability and explorative behaviors. The findings showed that the vaccine affected the production of several neurochemical factors, namely NRG-1, neuregulin, and oxytocin. Our results support the claim regarding the safety of tetanus vaccination during pregnancy and its possibility as a preventive of ASD development. Nevertheless, additional examinations are needed to confirm our preliminary results. Additionally, further studies are needed to confirm the safety of tetanus toxoid on fetal development.

\section{Conflicts of Interest}

No potential conflict of interest relevant to this article was reported.

\section{Author Contributions}

Conceptualization: Ferit Durankuş and Eda Sünnetçi. 
Conducting the experiment: Oytun Erbaş, Özüm Atasoy, and Mümin Alper Erdoğan. Statistical analysis: Oytun Erbaş. Writing-manuscript: Eda Sünnetçi and Yakup Albayrak.

\section{ORCID}

Eda Sünnetçi https://orcid.org/0000-0002-6871-8858

Ferit Durankuş https://orcid.org/0000-0002-3337-8419

Yakup Albayrak https://orcid.org/0000-0002-1926-1695 Mümin Alper Erdoğan

https://orcid.org/0000-0003-0048-444X

Özüm Atasoy https://orcid.org/0000-0001-5115-7815

Oytun Erbaş https://orcid.org/0000-0002-2515-2946

\section{REFERENCES}

1. Kohane IS. An autism case history to review the systematic analysis of large-scale data to refine the diagnosis and treatment of neuropsychiatric disorders. Biol Psychiatry 2015;77: 59-65.

2. Matson JL, Goldin RL. Diagnosing young children with autism. Int J Dev Neurosci 2014;39:44-48.

3. Song L, Luo X, Jiang Q, Chen Z, Zhou L, Wang D, et al. Vitamin $D$ supplementation is beneficial for children with autism spectrum disorder: a meta-analysis. Clin Psychopharmacol Neurosci 2020;18:203-213.

4. Oh DH, Kim IB, Kim SH, Ahn DH. Predicting autism spectrum disorder using blood-based gene expression signatures and machine learning. Clin Psychopharmacol Neurosci 2017;15: 47-52.

5. Saad K, Eltayeb AA, Mohamad IL, Al-Atram AA, Elserogy Y, Bjørklund $\mathrm{G}$, et al. A randomized, placebo-controlled trial of digestive enzymes in children with autism spectrum disorders. Clin Psychopharmacol Neurosci 2015;13:188-193.

6. Wegiel J, Kuchna I, Nowicki K, Imaki H, Wegiel J, Marchi E, et al. The neuropathology of autism: defects of neurogenesis and neuronal migration, and dysplastic changes. Acta Neuropathol 2010;119:755-770.

7. Lee JH, Espinera AR, Chen D, Choi KE, Caslin AY, Won S, et al. Neonatal inflammatory pain and systemic inflammatory responses as possible environmental factors in the development of autism spectrum disorder of juvenile rats. J Neuroinflammation 2016;13:109.

8. Ashwood P, Krakowiak P, Hertz-Picciotto I, Hansen R, Pessah I, Van de Water J. Elevated plasma cytokines in autism spectrum disorders provide evidence of immune dysfunction and are associated with impaired behavioral outcome. Brain Behav Immun 2011;25:40-45.

9. Corradini I, Focchi E, Rasile M, Morini R, Desiato G, Tomasoni $\mathrm{R}$, et al. Maternal immune activation delays excitatory-to-inhibitory gamma-aminobutyric acid switch in offspring. Biol Psychiatry 2018;83:680-691.

10. Urakubo A, Jarskog LF, Lieberman JA, Gilmore JH. Prenatal exposure to maternal infection alters cytokine expression in the placenta, amniotic fluid, and fetal brain. Schizophr Res 2001;47:27-36.

11. Patterson PH. Immune involvement in schizophrenia and autism: etiology, pathology and animal models. Behav Brain Res 2009;204:313-321.

12. Xia Y, Qi F, Zou J, Yang J, Yao Z. Influenza vaccination during early pregnancy contributes to neurogenesis and behavioral function in offspring. Brain Behav Immun 2014;42:212-221.

13. Qi F, Yang J, Xia Y, Yuan Q, Guo K, Zou J, et al. A(H1N1) vaccination recruits $T$ lymphocytes to the choroid plexus for the promotion of hippocampal neurogenesis and working memory in pregnant mice. Brain Behav Immun 2016;53:72-83.

14. Xia Y, Qi F, Zou J, Yao Z. Influenza A(H1N1) vaccination during early pregnancy transiently promotes hippocampal neurogenesis and working memory. Involvement of Th1/Th2 balance. Brain Res 2014;1592:34-43.

15. Qi F, Zuo Z, Yang J, Hu S, Yang Y, Yuan Q, et al. Combined effect of BCG vaccination and enriched environment promote neurogenesis and spatial cognition via a shift in meningeal macrophage M2 polarization. I Neuroinflammation 2017;14:32.

16. Wu Y, Qi F, Song D, He Z, Zuo Z, Yang Y, et al. Prenatal influenza vaccination rescues impairments of social behavior and lamination in a mouse model of autism. I Neuroinflammation 2018; 15:228.

17. Mrozek-Budzyn D, Kiełtyka A, Majewska R. Lack of association between measles-mumps-rubella vaccination and autism in children: a case-control study. Pediatr Infect Dis J 2010;29:397-400.

18. Zerbo O, Qian Y, Yoshida C, Fireman BH, Klein NP, Croen LA. Association between influenza infection and vaccination during pregnancy and risk of autism spectrum disorder. JAMA Pediatr 2017;171:e163609.

19. Sukumaran L, McCarthy NL, Kharbanda EO, McNeil MM, Naleway AL, Klein NP, et al. Association of Tdap vaccination with acute events and adverse birth outcomes among pregnant women with prior tetanus-containing immunizations. JAMA 2015;314:1581-1587.

20. Becerra-Culqui TA, Getahun D, Chiu V, Sy LS, Tseng HF. Prenatal tetanus, diphtheria, acellular pertussis vaccination and autism spectrum disorder. Pediatrics 2018;142:e20180120.

21. Halladay AK, Bishop S, Constantino JN, Daniels AM, Koenig $\mathrm{K}$, Palmer K, et al. Sex and gender differences in autism spectrum disorder: summarizing evidence gaps and identifying emerging areas of priority. Mol Autism 2015;6:36.

22. Moy SS, Nadler JJ, Perez A, Barbaro RP, Johns JM, Magnuson $\mathrm{TR}$, et al. Sociability and preference for social novelty in five inbred strains: an approach to assess autistic-like behavior in mice. Genes Brain Behav 2004;3:287-302.

23. Ellegood J, Crawley JN. Behavioral and neuroanatomical phe- 
notypes in mouse models of autism. Neurotherapeutics 2015; 12:521-533.

24. Hrabovska SV, Salyha YT. Animal models of autism spectrum disorders and behavioral techniques of their examination. Neurophysiology 2016;48:380-388.

25. O'Donnell KJ, Meaney MJ. Fetal origins of mental health: the developmental origins of health and disease hypothesis. Am J Psychiatry 2017;174:319-328.

26. Bradford MM. A rapid and sensitive method for the quantitation of microgram quantities of protein utilizing the principle of protein-dye binding. Anal Biochem 1976;72:248-254.

27. Edlow AG. Maternal obesity and neurodevelopmental and psychiatric disorders in offspring. Prenat Diagn 2017;37:95-110.

28. Gepner B, Féron F. Autism: a world changing too fast for a mis-wired brain? Neurosci Biobehav Rev 2009;33:1227-1242.

29. American Psychiatric Association. Diagnostic and statistical manual of mental disorders. 5th ed. Washington, D.C.:American Psychiatric Association Publishing;2013.

30. Fazzari P, Paternain AV, Valiente M, Pla R, Luján R, Lloyd K, et al. Control of cortical GABA circuitry development by $\mathrm{Nrg} 1$ and ErbB4 signalling. Nature 2010;464:1376-1380.

31. Ryu J, Hong BH, Kim YJ, Yang EJ, Choi M, Kim H, et al. Neuregulin-1 attenuates cognitive function impairments in a transgenic mouse model of Alzheimer's disease. Cell Death Dis 2016;7:e2117.

32. Bertram I, Bernstein HG, Lendeckel U, Bukowska A, Dobrowolny $\mathrm{H}$, Keilhoff $\mathrm{G}$, et al. Immunohistochemical evidence for impaired neuregulin-1 signaling in the prefrontal cortex in schizophrenia and in unipolar depression. Ann NY Acad Sci 2007; 1096:147-156.

33. Pöyhönen S, Er S, Domanskyi A, Airavaara M. Effects of neurotrophic factors in glial cells in the central nervous system: expression and properties in neurodegeneration and injury. Front Physiol 2019;10:486.

34. Ikawa D, Makinodan M, Iwata K, Ohgidani M, Kato TA, Yamashita $\mathrm{Y}$, et al. Microglia-derived neuregulin expression in psychiatric disorders. Brain Behav Immun 2017;61:375385.

35. Erbas O, Erdogan MA, Khalilnezhad A, Gürkan FT, Yiğittürk G, Meral A, et al. Neurobehavioral effects of long-term maternal fructose intake in rat offspring. Int I Dev Neurosci 2018; 69:68-79.

36. Vargas DL, Nascimbene C, Krishnan C, Zimmerman AW, Pardo CA. Neuroglial activation and neuroinflammation in the brain of patients with autism. Ann Neurol 2005;57:67-81.

37. Jyonouchi H, Geng L, Streck DL, Toruner GA. Children with autism spectrum disorders (ASD) who exhibit chronic gastrointestinal (GI) symptoms and marked fluctuation of behavioral symptoms exhibit distinct innate immune abnormalities and transcriptional profiles of peripheral blood (PB) monocytes. J Neuroimmunol 2011;238:73-80.

38. Saghazadeh A, Ataeinia B, Keynejad K, Abdolalizadeh A, Hirbod-Mobarakeh A, Rezaei N. A meta-analysis of pro-in- flammatory cytokines in autism spectrum disorders: effects of age, gender, and latitude. J Psychiatr Res 2019;115:90-102.

39. Koehl MA. Ecological biomechanics of benthic organisms: life history, mechanical design and temporal patterns of mechanical stress. J Exp Biol 1999;202(Pt 23):3469-3476.

40. Elizalde N, Pastor PM, Garcia-García AL, Serres F, Venzala E, Huarte J, et al. Regulation of markers of synaptic function in mouse models of depression: chronic mild stress and decreased expression of VGLUT1. I Neurochem 2010;114: 1302-1314.

41. O'Mahony SM, Marchesi JR, Scully P, Codling C, Ceolho AM, Quigley EM, et al. Early life stress alters behavior, immunity, and microbiota in rats: implications for irritable bowel syndrome and psychiatric illnesses. Biol Psychiatry 2009;65: 263-267.

42. Masi A, Quintana DS, Glozier N, Lloyd AR, Hickie IB, Guastella AJ. Cytokine aberrations in autism spectrum disorder: a systematic review and meta-analysis. Mol Psychiatry 2015;20:440-446.

43. Chez MG, Burton Q, Dowling T, Chang M, Khanna P, Kramer C. Memantine as adjunctive therapy in children diagnosed with autistic spectrum disorders: an observation of initial clinical response and maintenance tolerability. I Child Neurol 2007;22:574-579.

44. Bałkowiec-Iskra E, Vermehren-Schmaedick A, Balkowiec A. Tumor necrosis factor- $\alpha$ increases brain-derived neurotrophic factor expression in trigeminal ganglion neurons in an activity-dependent manner. Neuroscience 2011;180:322-333.

45. Lin J, Sun J, Wang S, Milush JM, Baker CAR, Coccia M, et al. In vitro proinflammatory gene expression predicts in vivo telomere shortening: a preliminary study. Psychoneuroendocrinology 2018;96:179-187.

46. Jones C, Barrera I, Brothers S, Ring R, Wahlestedt C. Oxytocin and social functioning. Dialogues Clin Neurosci 2017;19: 193-201.

47. Maud C, Ryan J, McIntosh JE, Olsson CA. The role of oxytocin receptor gene (OXTR) DNA methylation (DNAm) in human social and emotional functioning: a systematic narrative review. BMC Psychiatry 2018;18:154.

48. Gulliver D, Werry E, Reekie TA, Katte TA, Jorgensen W, Kassiou M. Targeting the oxytocin system: new pharmacotherapeutic approaches. Trends Pharmacol Sci 2019;40:22-37.

49. Tully J, Gabay AS, Brown D, Murphy DGM, Blackwood N. The effect of intranasal oxytocin on neural response to facial emotions in healthy adults as measured by functional MRI: a systematic review. Psychiatry Res Neuroimaging 2018;272: 17-29.

50. Ruthschilling CA, Albiero G, Lazzari VM, Becker RO, de Moura AC, Lucion AB, et al. Analysis of transcriptional levels of the oxytocin receptor in different areas of the central nervous system and behaviors in high and low licking rats. Behav Brain Res 2012;228:176-184.

51. Andari E, Hurlemann R, Young LJ. A precision medicine ap- 
proach to oxytocin trials. In: Hurlemann $R$, Grinevich V, editors. Behavioral pharmacology of neuropeptides: oxytocin. Cham:Springer;2017. p. 559-590.

52. Peris J, MacFadyen K, Smith JA, de Kloet AD, Wang L, Krause EG. Oxytocin receptors are expressed on dopamine and glutamate neurons in the mouse ventral tegmental area that proj- ect to nucleus accumbens and other mesolimbic targets. J Comp Neurol 2017;525:1094-1108.

53. Barrett CE, Arambula SE, Young LJ. The oxytocin system promotes resilience to the effects of neonatal isolation on adult social attachment in female prairie voles. Transl Psychiatry 2015;5:e606. 